Article

\title{
Fashion Rental: Smart Business or Ethical Folly?
}

\author{
Ciara Gyde and Lisa S. McNeill * (1)
}

Department of Marketing, Otago Business School, University of Otago, P.O. Box 56, Dunedin 9054, New Zealand; ciara.gyde@postgrad.otago.ac.nz

* Correspondence: lisa.mcneill@otago.ac.nz

Citation: Gyde, C.; McNeill, L.S. Fashion Rental: Smart Business or Ethical Folly? Sustainability 2021, 13, 8888. https://doi.org/10.3390/ su13168888

Academic Editors: Kirsi Niinimäki and Natalia Moreira

Received: 11 June 2021

Accepted: 4 August 2021

Published: 9 August 2021

Publisher's Note: MDPI stays neutral with regard to jurisdictional claims in published maps and institutional affiliations.

Copyright: (c) 2021 by the authors. Licensee MDPI, Basel, Switzerland. This article is an open access article distributed under the terms and conditions of the Creative Commons Attribution (CC BY) license (https:// creativecommons.org/licenses/by/ $4.0 /)$.

\begin{abstract}
The research presented here illustrates the spectrum of fashion rental PSS firms and business strategies within the New Zealand fashion rental market. The evidence collected suggests that there is a market for fashion rental; however, this market is underdeveloped in regard to its potential as a benefit exchange medium that encourages alternative consumption practice. This study finds that there is, indeed, enormous potential in PSSs as a means to divert fashion-conscious consumers away from ownership behaviours; however, the current systems fall short of this goal. This study offers a taxonomy to create and develop fashion rental PSSs that achieve central aims of circular economy fashion systems, enhancing the collective, social aspects of access, value-sharing and continuing development of mutual gain within the system. It is anticipated that this taxonomy could be further refined and extended through research in other countries, including those with more established, larger fashion rental organisations. Further, there is potential for action research approaches to the design and analysis of alternative fashion rental PSSs.
\end{abstract}

Keywords: sustainable fashion; rental; product-service systems (PSS); taxonomy

\section{Introduction}

The textile industry is a significant sector of the global economy, with the USD 1.3 trillion clothing industry employing more than 300 million people along the value chain [1]. Yet, business enterprises in the fashion industry are responsible for significant negative environmental outcomes, including: contributing to resource depletion, producing large amounts of solid waste, pollution from chemical treatments used in dyeing and the disposal of large amounts of unsold stock through incineration or landfill deposits [2]. Collectively, the greenhouse gas emissions from textile production totalled one billion tonnes of $\mathrm{CO} 2$ equivalent, more than that of all international flights and maritime shipping combined [3]. Product-service system (PSS) models, such as renting, have begun to be adopted in the fashion industry as they are perceived to offer more sustainable consumption alternatives than fashion ownership [4]. PSSs as business practices are expected to lead to environmental benefits, but only if these models replace a significant volume of purchases and the rented goods are high enough quality to be resistant to intensive usage [5]. In consumer rental practice, however, there is still debate as to the balance found between the unintended impacts of the system itself and the benefits of a move toward multiple users of single garments [6]. To address this balance, examination of the factors required to engender a shift from linear to circular thinking in the fashion industry is required [7].

\section{Background}

\subsection{The Linear Fashion Industry}

Our global resources are finite, and the fashion system has long consumed more than its fair share of these resources. The production and distribution of most clothing operates in a linear way, where valuable virgin resources are converted into waste throughout the value chain and fast fashion has a low-cost, high-volume focus, otherwise known as the 'take-make-dispose' model [8]. This linear approach means that more than 500 billion USD 
of value is lost every year due to clothing underutilisation and a lack of recycling, and the negative environmental and social impact of the fashion system continues to grow in an exponential fashion [1]. Linear consumption and production practices are beginning to be questioned not only in academia, but also by high-profile industry figures and consumers themselves. There is increasing interest in consuming apparel in a more sustainable way, including a move toward circular business models in fashion [9]. Compared to other large industries, the fashion sector has significant potential to achieve greater resource efficiency [10]; however, for the industry to actually achieve a sustainable trajectory, consumer behaviour must pivot toward more environmentally positive consumption methods. Conventional fashion retail business models and consumer patterns of consumption use and disposal must change markedly to usefully reduce the current impacts of the fashion industry [11]. Business model innovation is a path to achieving this change by establishing industry-specific, resource-efficient ways of creating and delivering customer value [12].

\subsection{Sustainable Fashion Business}

Innovating existing business models to be more sustainable has the potential to generate a competitive advantage for firms, whilst also delivering environmental and social benefits [13]. Many organisations are searching for alternative ways to create and deliver value to consumers, motivated by industry changes and increased consumer demand for more ethically-produced goods and services [14]. Sustainable business models are those that operate in harmony with the environment and society by creating, delivering and capturing (i.e., monetising) value in a win-win solution to the organisation-consumer relationship [15]. Thus, exploring how sustainable business model innovations are functionally implemented in specific markets, such as the fashion industry, is important to understanding their long-term viability. As part of the drive toward more sustainable consumption and production, Circular Economy Business Models (CEBMs) represent an alternative economic model that aims to keep products and materials at their highest utility and value, achieved through long-lasting design, maintenance, repair, reuse, remanufacturing, refurbishing and recycling $[12,15,16]$. CEBMs are a sustainability paradigm that challenges companies to revaluate and adapt their supply chains through maximising product value and usage. The gold standard of a CEBM is waste being avoided (reused) and only using renewable energy [12].

Where product-oriented businesses transition from linear to CEBM operations, a business model that is often employed is the Product-Service System (PSS) model [15]. This model focuses on selling performance instead of products as a means for realising the circular economy in a business context. PSS integrates products and services to fulfil customer needs through pay-per-use, short-term rental or long-term lease models. Use-orientated PSS business models for cars, bikes and tools have seen great success globally, leading scholars to question their potential in the fashion industry as well [17]. Internationally, the fashion PSS business model has taken off-Rent the Runway, one of the first American fashion rental firms, is currently valued at $\$ 1$ billion and fashion rental is expected to reach a market size of USD 1.9 billion by the end of 2023 [18]. Subsequently, big brands are beginning to jump on fashion's rental trend, with retailers such as Urban Outfitters launching Nuuly and Banana Republic offering Style Passport and My List at Bloomingdale's [19].

In fashion, PSSs encompass a range of forms. Essentially, PSS fashion systems are systems of access to fashion that prioritise use over ownership of fashion goods [9]. Defined as a business proposition that consists of "a mix of tangible products and intangible services" combined to jointly fulfil customer needs [6], PSSs in fashion encompass systems such as clothing consultancy, renting, swapping [9], garment 'take-back' and redesign [20]. In terms of formalised, for-profit business models, fashion PSSs propose new methods of value creation by shifting focus from the forward supply chain to the value-in-use experienced by the consumer [15]. Fashion rental is considered as a PSS model that enhances sustainable outcomes by dealing with the two key emerging challenges for apparel retailers: to reduce waste and to increase customer satisfaction with less material 
consumption [20]. Fashion PSS models have renewed hope in sustainably-oriented circles of delivering both social well-being and economic prosperity, while operating within the limits of the planet [21]. In this sense, fashion rental can provide a pathway for alternative apparel consumption behaviours, whilst decreasing the environmental impacts of the consumption of fashion generally by weighting service-oriented access to performance over ownership (and disposal) [22].

\subsection{PSS Fashion Models}

Fashion PSS business models are a functional means toward creating a 'lease society', and if appropriately applied, they have the potential to decrease the total number of garments consumed by providing alternative modes of product usage. Fashion rental services fulfil customer needs through a combination of tangible products and intangible services [9] whereby consumers pay for access to garment functions instead of ownership, satisfying consumer needs in a less materially-intensive way (and ultimately slowing resource loops) [15]. It is acknowledged in the sustainable fashion initiative that consumers are at the core of successful business models, with consumer acceptance of, and motivation toward, rental fashion heavily influencing business development in this field [23]. A wealth of recent literature thus extensively explores consumer attitudes toward fashion rental services [22,24-27]. However, less work has explored how individual firms package and present their service offerings in this space. Now that fashion PSSs are becoming more common and more acceptable to a wider reach of consumers, it is timely to consider the underlying business of fashion rental from a long-term viability perspective.

Although PSSs can mitigate some of the material impacts of the fashion industry, by changing consumer behaviour toward garments, there are many challenges in PSS acceptance and uptake by fashion businesses themselves. Pal \& Gander [28] argue that the introduction of more sustainable practices in fashion business models, such as renting, is likely to result in a reduction of profitability or the competitive ability of firms if only a niche of consumers is attracted to these value propositions. For smaller fashion rental businesses, the need to make medium to long-term investments can create difficulties and financial uncertainty [4]. In comparison to short-term profits generated at the point-of-sale in traditional fashion retail models, rental firms often encounter uncertainty of cash flow, particularly if the products selected are not popular or profitable with a somewhat fickle fashion customer base.

The core value proposition of the rental fashion system is in its ability to provide consumers with the use of a wide array of garments at a reduced cost, enabling access to designer pieces or varied styles with limited financial risk [29]. In this sense, value is both shared and extended, and offers potential for increased sustainability in the fashion industry overall. It is not a matter of debate that the clothing and accessory industries require innovation in business models to begin to significantly reduce environmental impact, and fashion rental PSS models are seen as one opportunity to achieve this [24]. Despite this promise, recent examination of PSSs more generally suggest that they do not automatically result in a decoupling of production from material and energy consumption, and that dematerialisation of the industry in which they operate is not always an outcome of the system [30]. When fashion products are provided within rental services, sustainable outcomes are sought through intensification of use. However, intensification of use is a double-edged sword in fashion rental PSSs, where increased laundering and transport of garments may in fact increase the lifecycle impact of individual garments beyond that if they were user-owned.

The move toward business models that eschew traditional linear production and consumption processes is fundamental to transition to more sustainable industries [31]. However, the difficulty of incentivising resource efficiency alongside user satisfaction in such models is still a central problem that remains unsolved for most systems [32]. Fashion rental PSS numbers have expanded exponentially around the world and continue to grow, yet still remain only a very small component of the entire fashion market [29]. 
Fashion goods become obsolete rapidly, irrespective of condition or quality [28]. Traditional PSS businesses, such as car rental or lease services, often have time on their side when obsolescence is measured. Further, traditional models that deal with higher-priced goods may include a servicing component at the cost of the customer. This is generally not the case in fashion rental, where damaged products are common and the extent of damage may render a product unusable. Studies show that consumers show lower product care within PSSs compared to ownership, and do not consider that they bear any responsibility for wear and tear and hidden damages that result in a shortened lifespan of goods overall [4,33].

Most PSS models are centred on a need to offer a wide range of high-quality stock to meet consumer demand, whilst also encouraging a high utilisation rate per item to mitigate environmental impacts [4]. The product use intensity of fashion products, however, demands detailed upkeep of products, such as professional cleaning, for product longevity and customer satisfaction [24]. Each aspect of maintenance has an environmental cost, which must be factored into the overall sustainability assessment of the business model—for example, dry cleaning solvents contain highly toxic compounds and persistent pollutants when released, which may inhibit a firm's potential for sustainable outcomes [34]. Further, if fashion styles go out of circulation rapidly and new stock is required with increased intensity, intentions toward lowering the environmental cost of fashion may not be achieved. A sustainable fashion rental PSS should thus also be responsible for designing garment end-of-life strategies to ensure the longevity of materials and move close to a true CEBM.

Although rental businesses are not a new phenomenon per se, within the fashion industry, rental PSSs remain a fledgling alternative to the dominance of traditional goods acquisition channels. Fashion, as a product, is so invasive that the environmental and social externalities of 'fast fashion' contribute to reinforcing traditional ownership models, which diminish the attractiveness of PSS-based solutions [21]. Due to ongoing technological advancements, producing fashion goods from raw virgin materials becomes ever cheaper and faster, reducing the cost-effectiveness and attractiveness of PSS systems as a fashion retail alternative for many $[12,35,36]$. However, modes of sharing, renting, swapping or lending have been reinvented in recent years, and rental fashion enabled by technology is said to have the ability to change the future of fashion consumption [5].

Consumer motivations to engage in PSSs both generally and specifically in fashion rental PSSs have been studied, with general agreement that the majority of fashion rental consumers primarily value the economic and functional benefits of the system $[25,26,29]$. Other non-monetary intangible perceived consumer benefits of the rental system include a desire for change and new experience, social aspects of the model and the relative advantage of access to garments for fashion-conscious consumers [24,29,37-39]. There remains, however, a gap in knowledge regarding how fashion rental PSS providers view the value creation aspect of their offer, and what motivates them to continue in this space. Despite a wealth of literature examining consumer attitudes toward rental fashion, particularly in North American and European markets [22,28,39], less is known about how viable this industry is long-term for the businesses within it. Recent Swedish studies of fashion PSS rental models and firm implementation barriers for fashion rental services have emerged [22], but there is a paucity of work that extends beyond Europe and the US, including work that covers small to medium-sized rental enterprises that centre on one-off rentals rather than the subscription models utilised by larger and arguably higher profile first-mover firms such as Rent-the-Runway.

When alternative consumption practice is considered from a business strategy perspective, models for success in collaborative and sharing economies are few and fragmented. Recent examination of the disruptive landscape of alternative consumption offers the Communities of Benefit Exchange (CoBE) taxonomy as a means to detail the required exchange dimensions, including the nature of gain and benefit for all parties, and the channel structure required to create joint value for consumers and firms [40]. PSS models, specifically, are yet to be considered under this taxonomy, which indicates potential for developing frameworks for business viability as well as sustainability objectives in fashion 
rental PSSs. To achieve this, it is first necessary to conceptualise a framework for mutual acceptance and success of the fashion rental PSS by consumers and those organisations that offer them.

Although the New Zealand market for rental fashion is comparatively new when compared to that of other countries, signs indicate an increasing interest in rental fashion from both companies and customers. PSS rental fashion models have caught the interest of New Zealand firms, with some new fashion start-ups focusing entirely on the renting concept. The New Zealand rental fashion market differs markedly from that of international markets, with a small population size and geographically close proximity of consumers around the country, combined with a relatively high number of local fashion design startups per head of population. Adding to the growing interest in rental fashion is the fact that New Zealand remains relatively limited in regard to the infiltration of large fast fashion brands when compared to most European or North American markets (and even compared to its close neighbour, Australia) and continues to support a thriving local fashion industry in most regions. Further, even at the international designer end of the scale, New Zealand consumers have more limited choice beyond their own country boundaries than Europe or the US, with far fewer large brands willing or able to ship goods to this part of the world, and a relatively high import tax on personal goods introduced in 2019 to combat the influx of overseas products in this market.

\subsection{Research Aims}

Every viable organisation is built on a sound business model, underpinned with a unique selling proposition, stable customer base and competitive advantage [41]. In the context of the rental fashion business, while the unique selling proposition may be clear for some consumers, there is still a gap in understanding of what other aspects of the business proposition are required to make a success of a circular approach to fashion retailing. The creation of value is paramount to the PSS business, yet little is known regarding firm construction of value in the rental fashion market, specifically when linked to the deselection of ownership in the fashion consumption model. Although PSSs embody values of the circular economy, they may not equate to sustainable outcomes. While there is research that claims PSSs offer a more sustainable consumption alternative in consumer goods markets, there are comparatively few studies that address PSS business practices specifically, identifying factors in context that may influence environmental performance.

In the modern world, sustainability outcomes are important factors in determining a business's long-term viability. In New Zealand, the current largest fashion rental company claims that their business model "offer[s] a sustainable way to stay on trend" (Designer Wardrobe, 2021). However, there is little specific information on how businesses such as this have benchmarked such claims and what forms of operations actually do achieve sustainability outcomes in the fashion context. Overall, there is an urgent need to identify whether PSSs and fashion rental can simultaneously deliver economic benefit for firms while decreasing excess consumption, waste and unsustainable production practices. This study thus aims:

1. To conceptualise the framework of the business models underpinning fashion rental PSS firms;

2. To understand the creation and delivery of value within the PSS rental fashion model;

3. To examine these PSS models in the context of sustainability; and

4. To construct a benefit exchange taxonomy for rental fashion PSS firms to achieve business viability alongside sustainability outcomes.

\section{Methodology}

A qualitative approach to data collection was employed as it allowed an in-depth understanding of the phenomena at hand. To answer the research questions posed in this exploratory study of New Zealand fashion rental firms, the object of data collection 
was the production of rich, detailed first-hand accounts of the experience and phenomena under investigation [42]. In-depth interviews offered the opportunity to develop a research relationship with firm representatives, which also provided scope for follow-up questions and requests for additional information.

\subsection{Sample}

In total, representatives from ten fashion rental organisations took part in this study from cities throughout the country. While the number of participants is relatively few, this represented a near census of currently operating rental fashion organisations in $\mathrm{New}$ Zealand and gave a diverse sample of small, local, owner-operated businesses through to large international firms, as well as registered and unregistered businesses (including 'hobby' businesses who operate outside of the taxation system). To define firm size, Instagram reach was deemed an appropriate metric. According to prior literature, Instagram followers reflect network size and serve as an indication of popularity [43]. The higher the number of followers, the stronger the elicited brand effects, and the larger the reach of the commercial message [44] (refer Table 1 for sample characteristics).

Table 1. Sample Characteristics.

\begin{tabular}{cccccc}
\hline Firm & Region & Relative Reach * & Type/Garment Level ** & Registered & Informant \\
\hline Firm A & Hamilton & Small $(5.1 \mathrm{k})$ & Apparel/B & Yes & Founder-CEO \\
Firm B & Taupo & Medium $(5.8 \mathrm{k})$ & Apparel/A & No & Founder \\
Firm C & Hamilton & Small $(4.6 \mathrm{k})$ & Apparel/A + B & Yes & Founder-CEO \\
Firm D & Dunedin & Medium $(5.7 \mathrm{k})$ & Apparel/B & No & Founder \\
Firm E & Timaru/ & Medium $(10.1 \mathrm{k})$ & Apparel/B & Yes & Founder-CEO \\
Firm F & Dunedin & Small $(4.8 \mathrm{k})$ & Apparel/B & Yes & Founder-CEO \\
Firm G & Auckland & Small $(5.1 \mathrm{k})$ & Apparel/A & Yes & Owner-CEO \\
Firm H & Hamilton & Medium $(6.5 \mathrm{k})$ & Apparel/A + B & Yes & Owner-CEO \\
Firm I & Christchurch/Auckland & Small $(5.1 \mathrm{k})$ & Apparel/A + B & No & Founder \\
Firm J & Auckland & Large $(63.3 \mathrm{k})$ & Apparel \& & Yes & CEO \\
\hline
\end{tabular}

* (Firm sizes based on Instagram reach—small: 1-5.5 k followers, medium: $<5.5 \mathrm{k}-15 \mathrm{k}$, large: $<15 \mathrm{k}$ ); ${ }^{* *}$ (Garment level—A = Designer garments [>NZD 900]; B = Upper level high street [NZD 250-900]).

A semi-structured interview protocol was developed from an analytic framework that identified the key criteria for environmental sustainability in PSS businesses. Key criteria identified in prior theory formed the orientating concepts for the interview and analysis [5], namely: the use of durable, quality goods [5,45]; intensified use of goods [45]; enabling repair, recycling \& re-use [46]; stimulation of rental over ownership values, including hyper consumption, inducement and rebound [5,45,47]; and minimisation of packaging and transport [5,45-47].

\subsection{Analysis}

Braun and Clarke's [48] approach to thematic analysis was used to analyse transcribed interview data. Initial codes were generated from extant theory, and inductive coding was used to identify key themes within the data. After a primary round of analysis, interviews were reanalysed to refine and confirm themes and prepare the initial conceptual model.

\section{Results \& Discussion}

\subsection{The Fashion Rental PSS Business Model}

Participant interviews confirmed four baseline success factors on which any foundation for fashion rental success must be built, namely: a careful selection and curation of goods; a model that intensified use of goods, thereby extending lifecycle; a streamlined access system that minimised negative environmental perceptions; and marketing systems designed to promote and support behaviour change (refer to Figure 1). Operating to moderate the likely success of any fashion rental firm, despite adherence to these baseline 
success strategy factors, however, were the firms' abilities to manage uncertainty and risk (particularly financial) and effective inventory management procedures, as well as consumer perceptions of ownership, anxiety regarding the system, and psychological barriers toward sharing. Further, the trust of each party in the rental structure was central to acceptance of the model as a replacement for traditional fashion retail.

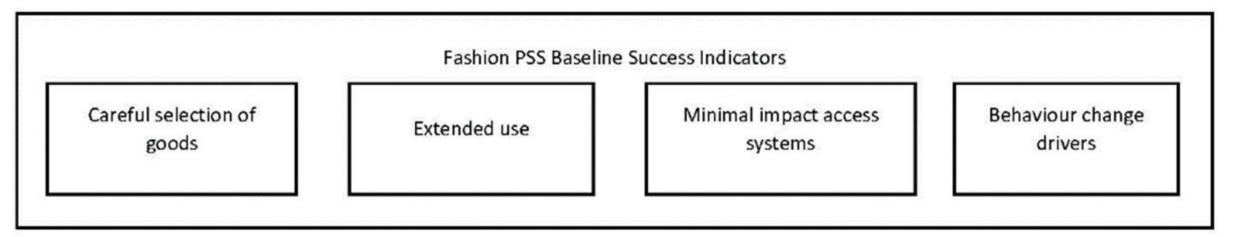

Figure 1. Fashion Rental PSS Baseline Success Indicators.

Selecting durable, high-quality goods is essential for any consumer products firm operating in the rental space. All participants in this study cited this as the primary baseline success indicator for a new rental fashion start-up, consistent with studies of consumer requirements in this space [4,39]. For some, this meant developing a means to determine how many 'rents' a product would stand up to, using key indicators such as the ability to easily clean fabrics to make this judgement: "Something that's more, let's say, super durable, they last for fucking ever. I can get 20 rents out of one dress [like this], it's super easy, manageable to clean, the stains come out of it super easy, that sort of thing. So I definitely look for dresses [that are easy to clean] and I think most rental companies do; they look for ones that can be a lot more profitable. That's how you do make your profit, is how many rents from one dress you can get ... I like durable fabrics that work for me as well" (Firm H).

This need for durable, easy to clean garments is in contrast to the nature of high-end fashion; however, delicate fabrics and complex treatments such as hand embellishments are valued above more utilitarian fabric presentations. If a consumer's desire is seated in the hedonic experience of accessing rare, delicate and unusual garments such as those provided in high-end or couture fashion, this presents a significant problem for rental fashion firms in meeting those expectations: "I hardly buy [those] things because I know a certain material from Rat and Boa that just pulls so easily on things-even jewellery will pull on it. I don't go for them really" (Firm F); "Zimmermann has a lot of the sheer chiffon material, which is super delicate... If people are good, you look at maybe getting 10 rents out of the one ... and getting that many rents out to either break even or make profit by saying that those dresses are really hard to maintain. One rip on it, you can't really salvage it" (Firm H).

Rental fashion in its essence is about intensely using garments [22]. However, rental firm operators' views on what constituted a lifecycle of a rental garment varied greatly, depending on the nature of the garment itself: "I try to keep it under 15, but it does depend on the quality again as to how long it stays in the collection" (Firm C); "In general, a good dress, I think you can get 30 rents. I would say-and there really good ones that you get in, you'd get 60 plus rents, I think maybe, if not well looked after, 15" (Firm H). Related to lifecycle of garments in rental fashion firms is the potential for negative resource efficiency through underutilisation of products [4].

Firms in this study estimated usage to sit at around $20 \%$, reaching $50 \%$ during busy periods such as Christmas and New Year holidays. In regard to fashion, low utilisation suggests a likelihood of garments reaching the end of a fashion lifecycle before their functional lifecycle ends-this may highlight a hidden sustainability cost of the model as well. Where participants discussed end-of-fashion life for garments, all indicated that they would attempt to sell the garment on the second-hand consumer market: "So I put them on my little Instagram selling page ... and then I might put some on Designer Wardrobe" (Firm A); "Then the ones that haven't gone out for a while, I will sell on Designer Wardrobe" (Firm E). The passing on of products deemed end-of-life to consumers 
by businesses is generally considered to decrease the environmental benefits of the rental model, as consumers are seen as less likely to responsibly recycle or dispose of goods than businesses can be expected to [46]. However, the redistribution of products with valid functional life remaining still offers some opportunity to close resource loops [15] by decreasing consumer reliance on new products whilst also increasing customer satisfaction: "They usually [sell] pretty quickly ... people want a good deal on designer stuff" (Firm E).

For rental fashion U-PSSs to be termed a sustainable alternative to traditional fashion retail, the means by which consumers access garments must be scrutinised in regard to the system's ability to minimise the impacts of channel components such as packaging and transport. Optimising transportation is a known key condition for achieving sustainable outcomes in consumer goods markets [5], as is the adoption of reusable or biodegradable packaging [4]. In this study, most firms admitted that this aspect of the PSS model was challenging and acknowledged its importance, but were yet to implement it: "It's a lot to cover as a business ... I don't want to have to pay for that extra cost. I am trying to find a way to better use the bags and not have to pay those label fees" (Frim D); "[I] just don't know the process. I really should just ask someone, but at the moment it hasn't been my priority" (Firm B); "I personally want to do it. When I get my returns back, it does make me kind of sad seeing all the bags that I just chuck in the rubbish" (Firm H).

Tellingly, the only rental fashion firm in this study to actively use and promote minimal impact access systems was Firm J, the largest and most established of the firms. Firm J espoused a desire to "go further with what we're doing" and discussed innovations in reusable delivery bags that they were trialling: "We have the benefit of, when we send something out, we're going to get that bag back as opposed to a typical retailer where it goes one-way. So with us, obviously they've got to send it back with the dress in. We're in a good position to capitalise on [reusable systems] because of the way rental works." Consumers are increasingly demanding sustainable, ethical business innovation in fashion systems [14]; hence, large firms, such as Firm J, may use sustainable packaging and transport systems as a point of difference, creating greater brand value overall.

\subsection{The Creation and Delivery of Mutual Value in the PSS Business Model}

General success indicators of PSS have been detailed in existing theory, noting how consumer value can be created; however, significantly less work has focused on the experience of PSS operators in the fashion industry, particularly those small- to medium-sized organisations that rent clothing on a one-off basis directly to consumers. In this study, several moderators of fashion rental PSS success were identified, from the value perspective of those operators attempting to establish a viable business in this way (Figure 2).

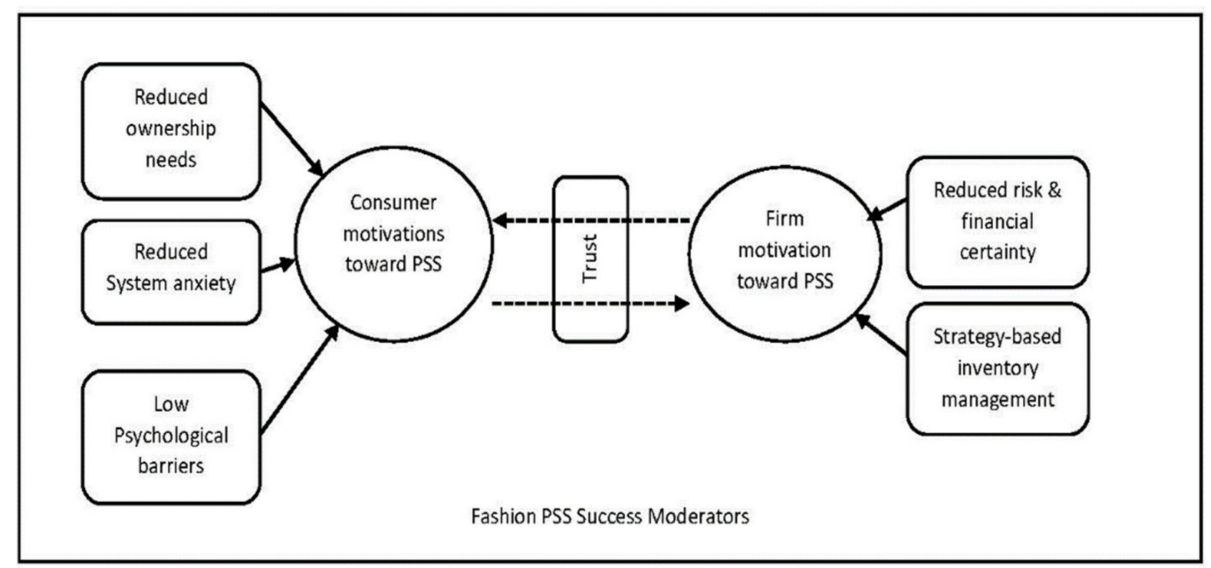

Figure 2. Conceptual framework for value creation in fashion rental PSSs. 


\subsection{Consumer Motivations toward Fashion Rental PSSs}

Studies of fashion consumers suggest that many are unwilling to abandon ownership of fashion products, often associating ownership with emotional symbolism and using clothing as a means for memory keeping [39]. This issue was noted by firms in this study, who agreed that some consumers wanted to own and keep garments for sentimental reasons: "Some girls, if it's a special occasion, they want to own the dress. I feel like for big occasions like that [graduations], some people, for the sentimental value, like, they want to own it. Yeah. And I know a few girls for the 21st stuff, they want to own the dress and not rent it" (Firm I). Despite the draw of ownership for customers in particular circumstances, the normalisation of social media as an indicator of identity was noted in the gradual movement away from owning a garment versus being 'seen' wearing a garment. As one firm noted: "The whole point of renting is girls want to wear a dress once and take a nice photo for Instagram" (Firm G).

Giving customers access to garments at the higher end of the fashion market, as well as the ability to frequently change garments through renting, was cited by firms as the primary drawcard of the fashion rental system. Participants were often reflecting on their own fashion desires when explaining the role of rental systems in increasing access to high-end garments: "I really struggled to keep up with the girls that I was friends with, they had a different lifestyle to me ... I was quite insecure ... so, I thought, 'Why don't I start something that I can do, not just for me, but for other girls out there like me, in a situation where they want to buy something but [it] was really expensive' ... I started with the hope of being able to keep up and also allow other girls to keep up too" (Firm F). While there is a certain social ethic to this sentiment, responses such as this do not align well with the call for more PSSs as a means to reduce consumption and waste overall. Study participants focused almost singularly on giving consumers access to products they could not afford or could not afford to rapidly replace (the 'wear once' for social media problem). None of the study's participants reflected on a sustainable ethos when describing their customers' needs, with many suggesting that their younger customers would use their service in a transitionary way until they could better afford to purchase garments themselves. If the central market positioning of fashion rental PSS is 'access' rather than 'reduction', the model misses the opportunity to challenge existing consumer perceptions and behaviours.

While fashion PSS models do offer access to garments, consumers are said to express anxiety toward these types of rental systems [22]. In this study, participants found that anxiety regarding liability for expensive garments often presented as a barrier for consumers considering the rental option: "Number one [barrier] would be people not wanting to rent something expensive because they're worried about the consumer agreement and if they ever ruin it, it comes out at a cost [to them]. I think that's a massive, massive thing" (Firm $\mathrm{H})$. However, only one firm had explicitly addressed this in their rental model, offering an added value service component termed 'rip and stain protection' (Firm J) at a small additional cost. It is interesting that this value-added service feature is unique to one firm, as all participants discussed the problem of damage fears: "People don't want to rent something expensive, because they're worried about the consumer agreement and if they ever ruin it, just some of the girls say 'I don't want to rent that one, because if I break it [it is too costly]"' (Firm H). As noted earlier, Firm J is the largest and most established firm in this study, with the greatest consumer following. The addition of service features such as the rip and stain protection may thus be outside of the scope of smaller firms who rent less garments overall and have lower levels of profitability.

A further point of system anxiety noted by firms in this study was in regard to assurance of availability of garments when required: "People are scared it's not going to get there on time to them-a lot of people email me and ask all the time 'Will this arrive on time?'"(Firm F). Most of the study participants described this aspect of consumer anxiety as out of their control ("I enjoy less that you are so dependent on someone sending the garments on time ... it's not fun having to break the news to someone that their dress 
might not arrive on time ... they get mad at you ... but I really can't do anything about $i^{\prime \prime}$ ), and minimal efforts were made to solve the problem ("I text everyone on a Sunday night, saying 'Can you please get this in the post?') (Firm E). Firm J, however, was the one firm who addressed the issue directly, with an automatic NZD 25 per day late penalty on tardy returns, as well as the opportunity for renters to also order a 'back-up dress' at a reduced rate. Firm J was the only in this study who did not note difficulties managing renters and returns, explaining that "What we've been committed to doing is just making the online experience a whole lot better and adding new features on top of that, including, you know, being able to rent a back-up dress, or having a fit guarantee, which is just to help mitigate all those potential disasters. You know, something not arriving, or it doesn't fit and not being able to get a refund or anything". Overall, Firm J is increasing revenue streams while creating added customer value in the rental system-something that is supported by their large reach and inventory. In this context, Firm G acknowledged the disparity between their offering and that of Firm J: "They offer so many sizes and styles ... I'm not in that place yet, where I can offer the same dress in 10 different sizes or colours".

Contamination of garments, i.e., hygiene and cleanliness, is a prominent psychological barrier to consumer adoption of rental fashion [39], and all of the participants discussed this issue in terms of ensuring customers receive a quality experience. Where firms differed, however, was in regard to how they maintained the cleanliness of their clothing-smaller firms tended to hand or machine wash garments themselves, with only the larger firms in the study using professional dry-cleaning services. Firms perceived separate cleaning fees as off-putting to consumers, both perceptually (in referencing hygiene) and financially. By incorporating cleaning costs into the rental fee, firms believed this in some way hid the negative connotations of others wearing the garment you may rent. Small firms in this study were particularly cognisant of the need to keep cleaning costs down, particularly as they were not able to benefit from bulk rates for professional cleaning in the way that larger firms might: "I do know rental companies [that] include dry cleaning price in the rental, which makes the rental obviously a lot more expensive. So, it's definitely something that I preferred to get in to, keeping my business, you know, cheap and affordable" (Firm H).

\subsection{Firm Motivation toward Fashion Rental PSSs}

Firm commitment to a PSS in fashion rental is also moderated by certain factors, although unlike those factors that impact consumer acceptance of the model, which are perceptual and often emotionally driven, the core moderating factors impacting firm acceptance are, for the most part, controllable by the firm. The need to take a medium- to long-term investment approach for purchasing stock can create short-term financial strain in the rental model, particularly when the inventory is particularly trend-based: "I basically put in all my savings from the year before to buy dresses. [Profit] was a lot slower than what I initially thought. I was thinking everyone would rent and I'd have all this money to buy new things, but it just definitely didn't go like that. It took a long time to build up to being as busy as we are currently" (Firm D).

The precariousness of financial stability in the rental business model was highlighted for many of the smaller firms in this study in their experience of COVID-19, where fashion rental business was prohibited in New Zealand during the country's major lockdown period: "We were like, oh fuck, this was like the worst timing. We're not going to make any money. We'd just paid for [the products] and we're like, 'No one's going to rent any dresses!'” (Firm B). In this way, the age of the firm in the market also becomes an important factor in ensuring moderation of financial risk. Firms who were relatively new required significant start-up capital to secure enough product for rental interest ("I think a lot more people are interested in renting off you once you've got more things to choose from" (Firm D)), whereas firms who were established cited a more comfortable financial position as they used profits from existing rentals to finance new stock: "[You need] a lot of start-up capital [to be competitive] as there's a lot of pretty well-established ones, rental firms, in New Zealand, that are constantly getting new stock in. I was quite fortunate that I started 
a couple of years ago, so I already had stock-it was easier to build up inventory from the profits off other dresses" (Firm C).

Alongside financial certainty, firm acceptance of the PSS fashion rental approach requires intensive inventory management processes. Building up an attractive and significant inventory was one challenge, but the challenge of other aspects of inventory management (such as delivery, cleaning and repair of garments) often did not become apparent until firms began to rent a significant volume of garments. This part of inventory management was seen as a double-edged sword-in one way, it was an indicator of success (through high product usage), and in another it was an increasingly difficult aspect of the system to maintain control over. Even those firms who made a decision to retain as many aspects of inventory management in-house as possible found that they still relied on other businesses: "The main thing that I really struggle with is I [am] kind of as a middleman, so although I do all the social media, I do all the dry cleaning, I do all the pickups and drop-offs, all that kind of jazz, I rely on a lot of other vendors to help me operate" (Firm G).

While extending product lifecycles via increased garment care is an expected aspect of the rental apparel system, a more immediate concern for those businesses setting up a fashion PSS, as well as those looking to develop their offerings, was the tension cited between clothing designers and manufacturers and fashion rental businesses. Essentially, consumers who engage in rental services are making a decision to not purchase a garment outright. All of the participants in this study detailed the negative backlash they had faced from those producing fashion garments toward their business: "[When buying from a popular designer] we were denied the sale, because we're a rental business" (Firm F); "They've got it stated in their terms and conditions that you're not allowed to buy dresses to rent" (Firm I). Some firms were pragmatic regarding this tension, acknowledging that fashion was a business driven by the potential for profit, and that the PSS model could be seen as cannibalising retail fashion. These firms were prepared to accept resistance from some brands and would reassort their buying to avoid these designers: "Because you know, we probably are taking away from the store to actually do sell, to sell at full price" (Firm E); "I guess if you're making a thousand dollars off one of their dresses and they're only making \$300, they would get a little bit annoyed" (Firm G).

However, a further perspective on the issue of designer-rental tension was offered by those who had spent more time in the PSS fashion industry, where they took a consumeroriented view, noting the potential for harmony between designers and PSS fashion models, with the aim of better meeting varied customer needs: "You probably introduce people to different brands as well, that they actually haven't been introduced to" (Firm E); "There are girls that are still wearing the brand, loving the brand, feeling amazing, and forming a connection with that brand"(Firm G); "I don't think there's any problem with renting because I think that it does expose people to new labels and new brands. It's good marketing for that brand" (Firm H). Participants of this study did not see themselves in direct competition with fashion designers and retailers, noting that there will likely remain a core group of consumers who prefer to own fashion garments. These participants saw potential for beneficial relationships with designers, viewing their PSS model as a type of 'gateway' to designer fashion for many consumers. Ideally, participants in the study proposed a future where the two fashion models worked together: "[The best scenario would be] offering collaborations in terms of when you purchase a large amount from them, they do a discount for you. Or if you have an agreement ... with the new season, they'll let you know when it's coming out and potentially send it out earlier" (Firm A).

The competition for consumer attention in the rental industry is said to be fierce, with one firm noting that New Zealand was a "saturated market, so many people are doing it" (Firm F). Firms in this study thus recognised that their success was dependent on targeted inventory strategies, most commonly by offering highly differentiated product lines: "I'm just looking at different stuff ... kind of veering off all the mainstream dresses, like ... I want to kind of create a little bit of a point of difference rather than just your standard stuff" (Firm A); "I try to get in dresses that the other rental firms don't have" (Firm B); "I 
think that I really try to stock different garments ... I really do try to offer something a little bit different in terms of dress" (Firm E); "I've always made sure that I'm getting in different stuff to what they're getting in" (Firm H).

Where differentiation did not occur, however, was in regard to pricing, where industry standards for single 'rents' of garments were known and firms maintained similar pricing structures to one another, regardless of their individual costs of doing business (such as those providers who had a physical store as well as a web presence versus those with only a web presence). Firms felt that keeping inventory management costs down was a significant element of their pricing structure, as their focus was on customer perceptions of affordability of the system: "[I need to] keep my business, you know, cheap and affordable, so that people don't feel like they're getting shammed out of the whole rental experience"(Firm B); "Girls, a percentage of them, are coming to rent a dress because they don't have much money" (Firm F). Respondents did, however, seek other ways to diversify their offerings in what they perceived as a crowded market. For example, one firm considered "Neon signs, like '21!' and stuff like that ... those selfie booths, photos and things like that. Hiring out of stuff really, because [events are] what my market is coming to me for" (Firm F), while another offered resale of second-hand garments, noting the complementarity of the two: "The marketplace and the rental side of things really complement each other ... it's been really great to have people rent from us and they end up, a large percent of them, end up buying from the marketplace when they were a first-time renter, and we fund the rental side of it too through the marketplace" (Firm J).

\subsection{The Mediating Role of Trust in Fashion Rental PSSs}

PSS approaches to business are not merely transactional. For a successful exchange of value, PSSs rely on between-party trust as a mediator of the long-term viability of the system. In the fashion rental PSS case, consumer-firm mutual trust mediates intentions by either party to continue in the system. From a firm perspective, the system relies on consumer care of garments as well as adherence to rules regarding use (one user per 'rent') and return of goods. Prior literature argues that the level of care consumers exhibit toward access-based products compared to those they own is diminished [33]. Participants in this study were keenly aware of the level of customer trust required when purchasing stock, with some opting to moderate their garment selection based on a perception of low customer care: "Sometimes I refrain from buying stuff in that high price bracket because some people just don't care for it, because it's not theirs to clean up, it's quite upsetting [for me] as well" (Firm A). Other firms saw garment damage as inevitable and a cost of doing business: "Girls are wearing the dresses to go to special events. They're dancing. They're having fun. That's life. Shit happens" (Firm G).

Just as firms expressed distrust of customer care in use of garments, rental service customers are said to be distrustful of the rental fashion system as a whole [22]. In this study, those firms who maintained a physical as well as online rental presence found that having a 'store front' mitigated some of the negative perceptions that consumers held toward renting garments. Stores allowed potential customers to inspect clothing for contamination, try on garments for fit, and talk to shop employees about the terms and conditions of rental. Further, rental stores replicated the traditional retail shopping experience, thus fulfilling the hedonic experience motivations that are often associated with fashion shopping [24]. Firm J, which currently operates three rental fashion stores, felt that this was an "awesome way to see for people to get trust how renting works" (Firm J).

However, the trust issue is not only in regard to customer trust of the system. All firms in this study noted the difficulty of managing the two-way logistics of rental fashion. Fashion rental PSS firms are reliant on customers returning garments on time, distribution services being reliable, and outsourced cleaning or repairs being completed promptly. The human factor in fashion rental tended to be the most significant challenge to the system cited: "People are frustrating with renting" (Firm H); "It gives me a bit of anxiety" (Firm 
E); "I feel like renting is so quick and easy and carefree, that sometimes those little things aren't at the forefront of someone's mind" (Firm G).

\subsection{The PSS Fashion Business Model \& Sustainability—Are the Two Mutually Exclusive?}

From a sustainability perspective, views of the fashion rental PSS providers detailed in this study highlight a core issue with this business model: that a focus on increased consumer access to fashion is not always well-aligned with reducing consumption and waste in the fashion system. For most of the participants in this study, the objective of their business was not to replace a traditional purchase model; rather, it was to provide an economic solution to consumer access problems with designer fashion: "People who rent these brands end up buying them at a later stage and what's happening with us ... They're actually renting a really high quality, great New Zealand designers and although they can't access that for purchase right now, [the brand will] be front of mind when they can afford to [buy]" (Firm J). This 'try-before-you-buy' mentality is in direct odds with principles of sustainable fashion systems and underlines key concerns that the rental fashion business may not be a realistic solution to our current issues of overconsumption and waste. The majority of PSS fashion businesses in this study did not express concern with the nature of the fashion industry more generally, instead focusing on a novel business model as a means to enter an already profitable market: "We don't want to think of ourselves as some sort of disruptor coming here to do this, you know, disrupt the whole industry, [we're here to] create a category that's right for everyone ... so we share the revenue that we get... we want it to be a partner to brands ... we didn't want to be just a disruptor" (Firm J).

Extant literature discusses how businesses can minimise the impacts of poor treatment of PSS goods by using more products; however, this is acknowledged as difficult in regard to clothing products [4]. This has led to some participants in this study choosing to accept garment loss and potentially low or negative profit margins on some garments, just to build their brand: “They don't tend to last as long and they need to get fixed quite often, but it's just the fact that they are so popular. You kind of have to make a choice ... they need to be mended quite often, but I'd still get them because they are so popular anyways" (Firm C). While this approach may work for larger, established firms, it may not be a manageable strategy for small or new fashion rental firms. Further, this issue highlights one of the hidden, unsustainable aspects of fashion rental: that of potentially accelerated disposal of garments that an individual consumer may have kept and cared for over a longer period of time.

In this study, the core focus of fashion PSS operators was to provide access to fashion products normally out of reach of all but a small group of consumers: "So I think as a company, it's nice to be able to buy them [dresses] for people to wear for a special event and then they don't have to worry about having the cost of it" (Firm D). In this way, participants saw themselves as offering a social service that transcended normal price-related barriers to the high fashion experience: "I really like just being in an environment where I can actually contribute something to someone else ... being able to have an experience where I can actually help people feel and look their best is quite rewarding" (Firm G); "[I get the] validity of making girls look and feel good ... feel really, really cool and amazing and take awesome photos and have these memories and really nice dress" (Firm H).

While more equality of access to fashion products is a significant benefit of the PSS fashion system, this aspect of the system was viewed as separate from sustainability or ethical use of apparel, missing the potential of promoting the system as a replacement for purchase rather than a means to access high fashion: "I know it's just a dress rental business. I'm not going to change the world. But people do feel really good and like a really nice dress, especially if they know that it's more expensive, and they couldn't afford to buy it" (Firm F). This view extended to the smaller owner-operators of the fashion PSSs themselves, who cited a major driver for their own choice to set up a rental fashion business as their desire to access garments: "I always brought designer dresses ... I love dresses" (Firm B); "[Now] I can make money and have beautiful dresses that I can wear whenever" 
(Firm I); "I guess I've always been into designer clothing ... I love, you know, being able to justify buying expensive things that are hard to justify as one-off purchase [by using the business as an excuse]" (Firm D).

Rental systems work well within categories of infrequently used goods $[4,22,28,31]$. Fashion can be split into two categories of use frequency-the high use, everyday garment (such as jeans and sweaters) and the infrequent or one-off use garment (such as wedding gowns or special occasion wear). In regard to behaviour change around fashion ownership, U-PSS rental fashion models predominantly target special occasion wear, or high-end fashion and couture. All of the firms in this study focused their business on garments that would likely only be worn once by a consumer, due to their distinctive nature or special features: "Girls tend to prefer just to rent a garment you're going to wear once rather than buying it and then wear it once just to sit in your wardrobe or you have to resell it" (Firm A).

While firms in this study recognised the sustainability benefits of reducing purchase of 'wear-once' garments ("It's just a good system to be honest. It has people reuse dresses and not have to have something once and then have it sit in your wardrobe or not be able to sell" (Firm E); "I managed to get in 10 dresses, which stopped 10 to 15 girls buying 10 to 15 dresses" (Firm H)), no firms discussed a strategy to extend the rental fashion model to include everyday garments. This is interesting as it points to a system currently limited by perceptions of the business owner or manager as rental fashion sitting within a tightly defined occasion-wear category. This in itself limits the overall sustainable benefit of such systems as the core problem of excess consumption of fashion products is not addressed in a broader fashion.

\section{Conclusions: Toward a Benefit Exchange Taxonomy for Fashion Rental PSSs}

If fashion rental is considered as a community of benefit exchange (CoBE), under Bajaj et al.'s [40] taxonomy of alternative consumption practice, the fashion rental PSS fits squarely within the Business Managed platform structure, with a clear organising strategy and intention of profit generation. The Business Managed platforms are ostensibly the most precarious of CoBE models as they are the most threatened from the network effect of consumer-orientated CoBE platforms, whereby individuals work together in a like-minded fashion to achieve beneficial outcomes for the group. Business Managed platforms tend to have a central purpose of pecuniary gain, whereas Consumer Managed or Business Endorsed platforms often also include the purpose of interaction, community focus, altruism and social sustainability [40]. This categorisation of the fashion rental PSS is, in itself, a key signal of what is required to create a truly sustainable and futurefocused fashion service model-an understanding of the nature of mutual gain and benefit between consumers and service providers. The results of this study identified core areas of disconnect between the nature of perceived gain and benefit for consumers to that of the PSS provider. This disconnect leads to a functional business model that may achieve business profitability in the short-term, yet does not align well with either the current move toward sustainable consumption alternatives in the fashion industry or long-term business growth and stability. Hence, this study offers a taxonomy for mutual benefit exchange in fashion rental PSSs, with the aim of providing future pathways to stabilise this alternative consumption model within the fashion system (Figure 3). 


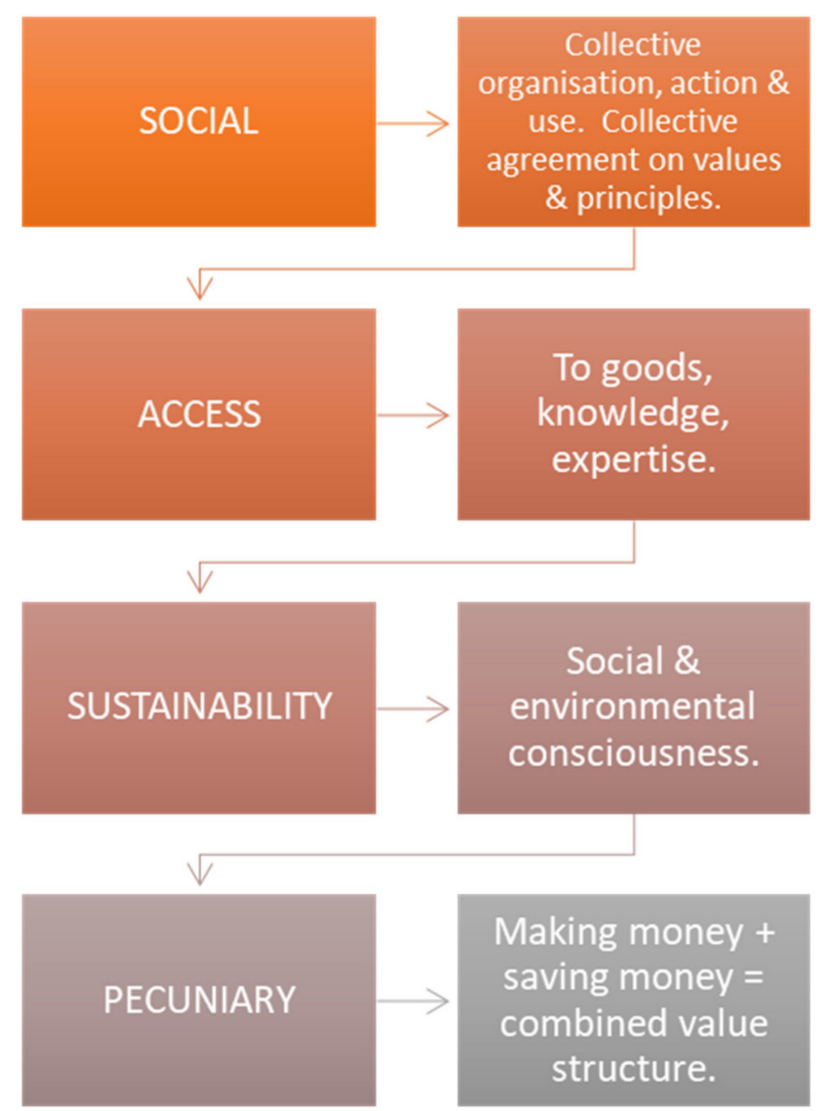

Figure 3. A benefit exchange taxonomy for fashion rental PSSs.

Prior literature has identified a significant consumer drive toward the non-monetary, intangible benefits of renting in the emerging fashion apparel world [24,29,37-39], including the social benefits of consumption communities. A conscious system design that embraces this within fashion PSSs would have a significant advantage over existing models in the apparel rental market. A focus on the social elements of a collaborative consumption service has benefited exiting organisations such as Uber and Airbnb, where users and providers are treated as equal members of the exchange platform (for example, with two-way review and feedback systems). Moving toward a collective organisation of the fashion rental PSS would allow features to be embedded to improve user connectedness with the system and community of other users, for designers to benefit from communally-beneficial supply and to enhance overall trust in the user-provider relationship (a core moderator of fashion PSS success identified in this study).

Access to goods, a primary driver for both consumers and providers of fashion rental PSSs, has been couched in economic understanding within these models, focusing on allowing consumer use of products they may not have otherwise afforded to purchase. This economic framing of access is not suitable within a long-term sustainable model of alternative consumption, where the term access should be centred on access to the outcomes of fashion use, including personal, social and ethical/environmental wellbeing. In this sense, access in a benefit exchange taxonomy for fashion rental should also embrace access to fashion knowledge and expertise, decoupled from simple ownership of garments. Enhancing this aspect of the fashion rental PSS model underpins the previous step of collective social good and stretches across users, producers (designers) and rental system providers.

Linked to access as well as the knowledge and expertise to value garment performance and use outcomes over ownership is a clear set of sustainability principles guiding the PSS as a whole. Currently, this is a particularly weak aspect of current fashion rental business models, which, despite acknowledging a growing consumer trend toward sustainable 
fashion alternatives, focuses almost exclusively on a profit-per-wear formula in regard to garment selection, maintenance and disposal. There remains significant potential for fashion rental PSS providers to consider the true environmental cost of their offerings and reconceptualise their model to focus less on economy of access and more on the social and sustainable benefits of their business model. By communicating this clearly to consumers, through the pillars of collective organisation, knowledge and expertise, the fashion model can genuinely move from one of ownership to value-sharing.

For models such as those described here to endure and grow in impact and use, there must still remain a pecuniary strategy that allows business operators to remain profitable. However, the taxonomy presented here contends that firm money-making considerations should not occur in isolation from a consideration of financial benefit to the consumer of these models. Creating mutual financial value may mean that businesses focus less on short-term increased profit margins and more on the long-term impact of the new PSS approach to fashion consumption. The hierarchy of social, accessible and sustainable values must be fulfilled in order for this to happen, and for the model to be truly 'smart business'.

Author Contributions: Conceptualisation, methodology and analysis, C.G. and L.S.M.; formal analysis and data collection, C.G.; writing-original draft preparation, L.S.M.; writing-review and editing, L.S.M.; supervision, L.S.M. Both authors have read and agreed to the published version of the manuscript.

Funding: This research received no external funding.

Institutional Review Board Statement: This study has been approved by the University of Otago Human Ethics Committee. Approval \# D20/335.

Informed Consent Statement: Informed consent was obtained from all subjects involved in the study.

Conflicts of Interest: The authors declare no conflict of interest.

\section{References}

1. Ellen McCarther Foundation. A New Textiles Economy: Redesigning Fashion's Future. ANBI. 2017. Available online: https: / / www.ellenmacarthurfoundation.org/ (accessed on 20 January 2021).

2. Quantis. Measuring Fashion. Environmental Impact of the Global Apparel and Footwear Industries Study; Quantis: Lausanne, Switzerland, 2018. Available online: https:/ / quantis-intl.com/report/measuring-fashion-report/ (accessed on 20 January 2021).

3. Mäkinen, K. Clothing Rental—Service Development Proposals through Service Design; Turku University of Applied Sciences: Turku, Finland, 2019. Available online: https:/ / www.theseus.fi/bitstream/handle/10024/226728/Makinen_Kaisa.pdf (accessed on 20 January 2021).

4. Retamal, M. Product-service systems in Southeast Asia: Business practices and factors influencing environmental sustainability. J. Clean. Prod. 2017, 894-903. [CrossRef]

5. Demailly, D.; Novel, A.S. The Sharing Economy: Make it Sustainable. Institut du Developpement Durable et des Relations Internationales. 2014, pp. 402-410. Available online: https://www.iddri.org/sites/default/files/import/publications/st0314_ dd-asn_sharing-economy.pdf (accessed on 20 January 2021).

6. Tukker, A.; Tischner, U. Product-service as a research field: Past, present and future: Reflection from a decade of research. J. Clean. Prod. 2006, 14, 1552-1556. [CrossRef]

7. Bocken, N.M.; Miller, K.; Weissbrod, I.; Holgado, M.; Evans, S. Slowing Resource Loops in the Clothing Industry through Circular Business Model Experimentation. In Sustainable Fashion in a Circular Economy; Alto ARTS Books: Helsinki, Finland, 2018; pp. 152-167. [CrossRef]

8. Clube, R.; Tennant, M. Exploring garment rental as a sustainable business model in the fashion industry: Does contamination impact the consumption experience? J. Consum. Behav. 2020, 19, 359-370. [CrossRef]

9. Lang, C.; Armstrong, C.M. Fashion leadership and intention toward clothing product-service retail models. J. Fash. Mark. Manag. 2018, 22, 571-587. [CrossRef]

10. Gwozdz, W.; Nielsen, K.; Müller, T. An environmental perspective on clothing consumption: Consumer segments and their behavioral patterns. Sustainability 2017, 9, 762. [CrossRef]

11. Niinimäki, K.; Peters, G.; Dahlbo, H.; Perry, P.; Rissanen, T.; Gwilt, A. The Environmental Price of Fast Fashion. Nat. Rev. Earth Environ. 2020, 1, 189-200. [CrossRef]

12. Mont, O.; Whalen, K.; Nussholz, J. Sustainable innovation in business models: Celebrated but not interrogated. In Handbook of Sustainable Innovation; Edward Elgar Publishing: Cheltenham, UK; Northhampton, MA, USA, 2019; pp. 124-140, ISBN 978-1-78811-256-7.

13. Bocken, N.; Rana, P.; Short, S. Value mapping for sustainable business thinking. J. Ind. Prod. Eng. 2015, 32, 67-81. [CrossRef]

14. Stahel, W.R. The Circular Economy: A User's Guide; Routledge: London, UK, 2019; ISBN 9780367200176. 
15. Ludeke-Freund, F.; Gold, S.; Bocken, N. A Review and Typology of Circular Economy Business Model Patterns. J. Ind. Ecol. 2018, 36-61. [CrossRef]

16. Johnson, E.; Plepys, A. Product-Service Systems and Sustainability: Analysing the Environmental Impacts of Rental Clothing. Sustainability 2021, 13, 2118. [CrossRef]

17. Pedersen ER, G.; Gwozdz, W.; Hvass, K.K. Exploring the relationship between business model innovation, corporate sustainability, and organisational values within the fashion industry. J. Bus. Ethics 2018, 149, 267-284. [CrossRef]

18. Daniel, J. Online Clothing Rental Market Future Scope, Revenue Growth, by Leading Companies, Regional Outlook 2019, Online Clothing Rental Market Size, Share \& Trends Analysis Report, by End Use (Men, Women), by Dress Code (Formal, Casual, Traditional), by Region, and Segment Forecasts, 2019-2025. Available online: https://www.marketdataforecast.com/marketreports/online-clothing-rental-market (accessed on 20 May 2021).

19. Anna Meyer. Available online: https:/ / www.inc.com/anna-meyer/urban-outfitters-nuuly-clothing-rental-business (accessed on 28 January 2021).

20. Armstrong, C.M.; Lang, C. Sustainable Product Service Systems: The New Frontier in Apparel Retailing? Res. J. Text. Appar. 2014, 17. [CrossRef]

21. Vezzoli, C.; Ceschin, F.; Diehl, J.C.; Kohtala, C. New Design Challenges to Widely Implement 'Sustainable Product-Service Systems'. J. Clean. Prod. 2015, 97. [CrossRef]

22. Borg, D.; Mont, O.; Schoonover, H. Consumer Acceptance and Value in Use-Oriented Product-Service Systems: Lessons from Swedish Consumer Goods Companies. Sustainability 2020, 12, 8079. [CrossRef]

23. Osterwalder, A.; Pigneur, Y. Business Model Generation: A Handbook for Visionaries, Game Changers, and Challengers; John Wiley \& Sons: Hoboken, NJ, USA, 2010; ISBN 978-0-470-87641-1.

24. Armstrong, C.M.; Niinimäki, K.; Kujala, S.; Karell, E.; Lang, C. Sustainable product-service systems for clothing: Exploring consumer perceptions of consumption alternatives in Finland. J. Clean. Prod. 2015, 30-39. [CrossRef]

25. Becker-Leifhold, C.; Iran, S. Collaborative fashion consumption-drivers, barriers and future pathways. J. Fash. Mark. Manag. 2018, 22, 189-208. [CrossRef]

26. Mukendi, A.; Henninger, C.E. Exploring the spectrum of fashion rental. J. Fash. Mark. Manag. Int. J. 2020, 24, 455-469. [CrossRef]

27. Park, H.; Armstrong, C.M. Is money the biggest driver? Uncovering motives for engaging in online collaborative consumption retail models for apparel. J. Retail. Consum. Serv. 2019, 51, 42-50. [CrossRef]

28. Pal, R.; Gander, J. Modelling environmental value: An examination of sustainable business models within the fashion industry. J. Clean. Prod. 2018, 251-263. [CrossRef]

29. Arrigo, E. Digital platforms in fashion rental: A business model analysis. J. Fash. Mark. Manag. 2021, 10, 1108. [CrossRef]

30. Corvellec, H.; Stål, H. Evidencing the waste effect of Product-Service Systems (PSSs). J. Clean. Prod. 2017, 145, 14-24. [CrossRef]

31. Edbring, E.G.; Lehner, M.; Mont, O. Exploring consumer attitudes to alternative models of consumption: Motivations and barriers. J. Clean. Prod. 2016, 123, 5-15. [CrossRef]

32. Kjaer, L.; Pagoropoulos, A.; Schmidt, J.H.; McAloone, T.C. Challenges when evaluating Product/Service-Systems through Life Cycle Assessment. J. Clean. Prod. 2016, 120, 95-104. [CrossRef]

33. Tunn, V.S.; Ackermann, L. Comparing consumers' product care in access and ownership models. Des. Soc. Des. Conf. 2020, 1, 2167-2176. [CrossRef]

34. Chen, H.-L.; Davis Burns, L. Environmental Analysis of Textile Products. Cloth. Text. Res. J. 2006, 248-261. [CrossRef]

35. Mont, O. Clarifying the concept of product-service system. J. Clean. Prod. 2002, 10, 237-245. [CrossRef]

36. Mont, O. Drivers and barriers for shifting towards more service-oriented businesses: Analysis of the PSS field and contributions from Sweden. J. Sustain. Prod. Des. 2002, 89-103. [CrossRef]

37. Lee, S.H.; Huang, R. Exploring the Motives for Online Fashion Renting: Insights from Social Retailing to Sustainability. Sustainability 2020, 12, 7610. [CrossRef]

38. Akbar, P.; Hoffmann, S. Under which circumstances do consumers choose a product service system (PSS)? Consumer benefits and costs of sharing in PSS. J. Clean. Prod. 2018, 201, 416-427. [CrossRef]

39. Armstrong, C.M.; Niinimäki, K.; Lang, C.; Kujala, S. A Use-Oriented Clothing Economy? Preliminary Affirmation for Sustainable Clothing Consumption Alternatives. J. Sustain. Dev. 2016, 18-31. [CrossRef]

40. Bajaj, N.; Ogden, S.; Steel, M.; Rahman, K. Communities of benefit exchange-A new taxonomy of alternative consumption practices. J. Consum. Behav. 2021, 1-19. [CrossRef]

41. Magretta, J. Why Business Models Matter. Harvard Business Review. 2002. Available online: https://hbr.org/2002/05/whybusiness-models-matter (accessed on 11 February 2021).

42. Pietkiewicz, I.; Smith, J. A practical guide to using interpretative phenomenological analysis in qualitative research psychology. Psychol. J. 2014, 20, 7-14. [CrossRef]

43. Agam, D.N. Followers Ratio on Instagram Affects the Product's Brand Awareness. Aust. J. Account. Econ. Financ. 2017, 3, 85-89.

44. Veirman, M.D.; Cauberghe, V.; Hudders, L. Marketing through Instagram influencers: The impact of number of followers and product divergence on brand attitude. Int. J. Advert. 2017, 5, 798-828. [CrossRef]

45. Leismann, K.; Schmitt, M.; Rohn, H.; Baedeker, C. Collaborative consumption: Towards a resource-saving consumption culture. Resources 2013, 2, 184-203. [CrossRef] 
46. Heiskanen, E.; Jalas, M. Can services lead to radical eco-efficiency improvements? A review of the debate and evidence. Corp. Soc. Responsib. Environ. Manag. 2003, 10, 186-198. [CrossRef]

47. Gottberg, A.; Longhurst, P.J. Exploring the potential of Product Service Systems to achieve household waste prevention on new housing developments in the UK. Waste Manag. Resour. 2010, 28, 228-235. [CrossRef] [PubMed]

48. Braun, V.; Clarke, V. Using thematic analysis in psychology. Qual. Res. Psychol. 2006, 3, 77-101. [CrossRef] 